\title{
Challenges of the control of opportunistic infections of zoonotic origin in HIVIAIDS patients
}

\author{
Yemisi Olukemi Adesiji ${ }^{1, ~ *, ~ J u l i u s ~ K o l a ~ O l o k e ~}$ \\ ${ }^{1}$ Department of Medical Microbiology and Parasitology, College of Health Sciences, Ogbomoso, Nigeria \\ ${ }^{2}$ Department of Microbiology and Immunology, All Saint University, Belair, Kingstown, St Vincent \& Grenadines
}

Email address:

drmrsadesiji@yahoo.com (Y. O. Adesiji)

\section{To cite this article:}

Yemisi Olukemi Adesiji, Julius Kola Oloke. Challenges of the Control of Opportunistic Infections of Zoonotic Origin in HIV/AIDS Patients. International Journal of Immunology. Special Issue: Immunotherapy. Vol. 3, No. 2-1, 2015, pp. 1-7.

doi: $10.11648 /$ j.iji.s.2015030201.11

\begin{abstract}
The HIV/AIDS pandemic is associated with a number of opportunistic infections of immunocompromised person. Some of these infections are recognized zoonoses that are naturally transmitted between animals and humans. These may be directly transmitted by, animals or indirectly by contact with contaminated food and water. Interactions between animals and humans have a complex interplay and health care providers should be aware of the potential role of animals as reservoirs of infectious diseases for HIV infected patients. The most frequent pattern of infection is characterized either by direct contact with farm or wild animals and/or ingestion of their products. Immunomodulatory antibodies that enhance the immune system to promote the function of immune cells have great promise in preventing and treating opportunistic infections of zoonotic origin in HIV/AIDS patient.
\end{abstract}

Keywords: Zoonosis, HIV/AIDs, Immunosuppression, Immunomodulatory Antibodies, Epidemiology

\section{Introduction}

An estimated 42 million individuals are currently infected with Human Immunodeficiency Virus (HIV) worldwide, with the vast majority of those in sub-Saharan Africa. About $3,200,000$ people are living with HIV/AIDS in Nigeria [1]. HIV can weaken the immune system to the point that the infected host is unable to control certain organisms that are usually controlled by a healthy immune system. Opportunistic pathogens are able to express their pathogenic effect only in association with predisposing factors that weaken the immune system. Some of these infections are zoonoses that are naturally transmitted between vertebrates animals and humans. Although many zoonoses have been diagnosed in patients with AIDS, although presence of infection does not necessarily indicate the source of the infection. Some zoonoses are species-specific, while others have a wide variety of vectors including pets, stray animals, farm animals, and humans. Many of these diseases can also be acquired from food and environmental sources and may have no relationship to pet ownership. Frequently, zoonotic infections diagnosed in people with AIDS are reactivations of latent infections and have no bearing on current contact with animal companions
[2]. A study that examined how frequently physicians and veterinarians encounter zoonotic diseases from pets and how often physicians and veterinarians communicate about zoonoses issues, of immunocompromised persons suggests that communication about zoonotic diseases is largely absent [3]. In many countries, appropriate policies regarding pet ownership and their effects on individual and community health are not usually practiced [4].

The incidence of transmission of zoonoses from animals is difficult to estimate in many countries. Some reports and prevalence studies carried out indicated that zoonotic infection contributed to appreciable level of morbidity and mortality in Nigeria while the risk is further increased by non-favourable ecological and human behavioural factors [5]. A number of animal-associated infections occur in persons infected with the human immunodeficiency virus (HIV), including those due to Toxoplasma gondii, Cryptosporidium, Microsporida, Salmonella, Campylobacter, Giardia, Rhodococcus, Mycobacterium bovis, M. marinum, Ringworm, Psittacosis, Pasteurella and Listeria monocytogenes. However, in this overview some of the common ones we often encounter in our environment will be mentioned. These are Mycobacterium, Campylobacter, Salmonella, Toxoplasma gondii, Cryptosporidium, Giardia and Microsporidia 
(TABLE 1). For effective control of opportunistic infectious disease that can easily occur in HIV or AIDS patients, it is critical to identify different scenarios in relation to human habits, epidemiological patterns and interplay between humans and animals in Nigeria.

The aim of this review is to outline the most important zoonoses that are significant in the epidemiology of AIDS and to provide a practical and manageable tool for health workers involved in the care of HIV-infected humans.

\subsection{Tuberculosis}

The World Health Organization estimates that 4.4 million people worldwide are infected with both Mycobacterium spp. and HIV and predicts one million deaths every year amongst this population [6]. The HIV/AIDS pandemic is associated with a number of opportunist mycobacterial infections, principally tuberculosis and disease due to the M. bovis and M. avium. Mycobacterium bovis is the causative agent of bovine tuberculosis. Given the rapidly spreading global human immunodeficiency virus (HIV) epidemic in developing countries, the WHO estimated that $70 \%$ (6 million) of humans co-infected with TB and HIV live in sub-Saharan Africa [7]. In Africa, however, bovine TB represents a potential health hazard to both animals and humans, as nearly $85 \%$ of cattle and $82 \%$ of the human population live in areas where the disease is prevalent or only partially controlled [8]. It has been shown that data available from most developing countries, mainly from sub-Saharan Africa, were insufficient to represent the true epidemiological picture of the disease [9]. Thus infection due to $\mathrm{M}$. bovis in humans is underreported as a result of the diagnostic limitations of many laboratories in distinguishing M. bovis from M. tuberculosis [10]. Accurate economic cost of bovine TB is not available in developing country [11]. However, data can be obtained from other countries where bovine TB is prevalent. In Argentina, for example, the annual loss due to bovine TB is approximately US\$63 million. 2 Based on these estimates, it can be inferred that bovine TB may pose a serious economic risk to Africa [10].

Tuberculosis occurring early in the course of HIV infection is usually caused by M. tuberculosis. However some cases are due to, M. bovis, which, in turn, is transmissible from man to animals, principally by the aerogenous route although the majority of cases in man are non-pulmonary [12]. The World Health Organization (WHO) ranks Nigeria as fourth among the 22 countries with the highest absolute number of TB cases. Collectively, these 22 countries have 80 percent of estimated TB cases worldwide. Nigeria had an incidence rate of 300 cases per 100,000 populations in 2008 . HIV-TB co-infection is also significant, with an estimated $27 \%$ of new adult TB patients being HIV positive [13].

It has been reported that $30-45 \%$ of HIV positive persons in Nigeria present with active TB at one point or the other [14], The first detailed study molecular types of M. tuberculosis complex strains from cattle and humans in Nigeria conducted in Ibadan, Oyo State revealed that approximately $13 \%$ of the disease from a total of 60 humans in this area was caused by strains of the RD9-deleted lineage (M. africanum type I and M. bovis) rather than $M$. tuberculosis [15]. The prevalence of bovine tuberculosis in Jigawa State, northwestern Nigeria using the comparative intradermal tuberculin test in 22 herds consisting of 922 cattle projected an overall and individual prevalence of $1.08 \%(10 / 922)$ and $45.45 \% \quad(10 / 22)$, respectively [16]. A study in 2010 assessed the risk of transmission of tuberculosis through milk. Five (1.25\%); $4 \mathrm{M}$. bovis and one M. africanum from 400 unpasteurized milk samples from north-central Nigeria were positive because drinking unpasteurized milk is a usual practice of some Nigerians [10] their report emphasizes that transmission between the animal and human reservoir is a serious threat [17]. Importance of tuberculosis in Nigerian patients infected with HIV has been previously reported $[18,19]$. In another similar study, the prevalence of $\mathrm{M}$. tuberculosis in people living with HIV in Osun state of Nigeria was found to be $25 \%$ using microscopy, $15 \%$ and $18.75 \%$ for $\mathrm{M}$. tuberculosis and $\mathrm{M}$. tuberculosis complex, respectively, suggesting there is overestimation of TB cases using microscopy. A positive association with occupation involving was also highlighted acquisition of M. avium complex infection [20].

In a study form Ibadan Nigeria, from 2005 to 2007, Mycobacterium tuberculosis Complex (MTC) strains were isolated from cattle, goats and pigs samples collected at the Bodija abattoir and from human samples from tuberculosis patients and livestock traders at the Akinyele cattle market in Ibadan, Southwestern Nigeria. Seventy four isolates obtained from humans (24) and livestock (50) were identified as MTC strains. Thirty two isolates were spoligotyped. Nineteen of these 32 isolates were identified as M. tuberculosis whilst 13 were identified as Mycobacterium bovis. Mycobacterium bovis was isolated from two humans, whereas M. tuberculosis was isolated from a bovine, a pig and a goat. Thirty two isolates were spoligotyped. Nineteen of these 32 isolates were identified as M. tuberculosis whilst 13 were identified as Mycobacterium bovis. Mycobacterium bovis was isolated from two humans, whereas M. tuberculosis was isolated from a bovine, a pig and a goat. All the M. bovis isolates identified in this study belonged to the Africa 1 clonal complex; the isolation of three M. tuberculosis strains from livestock raises the question of their epidemiological importance as a source of infection for humans [21]. These data indicate that higher incidence could have occurred in which diagnosis was not and more collaboration

\subsection{Campylobacter}

Bacteria belonging to the genus Campylobacter are Gram-negative microorganisms. They are among the most common pathogens isolated from patients with diarrhoea. The impact and importance of these micro-organisms in HIV infected or AIDS affected persons is relatively unknown, even if there is evidence that Campylobacter spp. in those people can represent a very important risk factor [22]. Campylobacter jejuni is the most common species isolated from HIV infected and AIDS affected people despite ample debate about the taxonomy of Campylobacter. 
In developing countries, Campylobacter is the most commonly isolated bacterial pathogen from children less than two years old with diarrhoea. The disease does not appear to be important in adults. In contrast, infection occurs in adults and older children in developed countries. Poor hygiene and sanitation and the close proximity to animals in developing countries all contribute to the easy and frequent acquisition of any enteric pathogen, including Campylobacter [23].

Most estimates of incidence in developing countries are from laboratory-based surveillance of pathogens responsible for diarrhoea. Campylobacter isolation rates in developing countries range from 5 to 20 percent [24]. Community-based case studies have provided estimates of 40000 to 60000 cases for every 100000 children younger than five [24, 25]. The genus Arcobacter has become increasingly important in recent years because its members have been considered emergent enteropathogens and potential zoonotic agents. They are aerotolerant Campylobacter-like organisms, previously classified as Campylobacter. Arcobacter shows an unusually wide range of habitats; and some species can be human and animal pathogens. Members of the genus Arcobacter were first isolated in 1977 from aborted bovine fetuses. [26]. The clinical relevance of Arcobacter in HIV infection has been previously documented [ 29]. Arcobacter has also been recovered in $1.5 \%$ of faeces samples from patients with diarrhoea affected by HIV and in $1 \%$ of from persons not affected [30]. The importance of Arcobacter as a potential opportunistic pathogen of zoonotic origin in HIV/AIDS patients may eventually become a matter of great concern in future. This view is based on the fact that in our laboratory we have consistently isolated Arcobacter from feacal samples of healthy chicken and pigs $(27,28)$. People acquire Arcobacter infection by ingestion of contaminated food or water and contact with pets. Infections due to Campylobacter spp. can be localized to the enteric environment or can generalize with bacteraemia and systemic involvement. Bacteraemia is more common in HIV-infected and AIDS affected people, the old, or infants of less than 12 months, and people with underlying disease, suggesting a close correlation between the onset of the disease and the immune status of the patient.

In order to reduce the risk represented by zoonotic agents to the consumer health, it is essential to reduce contamination of carcasses during the slaughtering processes particularly in food that will be administered to HIV and other immunocompromised individuals.

\subsection{Salmonella}

Salmonellae are widely considered one of the most ubiquitous pathogens, both in humans and animals. The most common species isolated are Salmonella typhimurium and Salmonella enteritidis [31] and infection often presents as recurrent diarrhoea with bacteraemia that relapses frequently despite therapy. Salmonellosis usually causes transient diarrhoea, but can also manifest as an asymptomatic bacteraemia, especially in children or when predisposing factors are present. In HIV-infected patients, salmonellosis is characterized by intense and long-lasting diarrhoea, which is frequently associated with septicaemia. Relapse of infection, with recurrent bacteraemia, is a common feature of AIDS patients [32]. The diagnosis of recurrent Salmonellae bacteraemia in a person at risk for AIDS has been recognized as an AIDS defining diagnosis which suggests underlying immune dysfunction with coincident HIV infection [33]. Non-typhoid septicaemia (NTS) is one of the most frequent manifestations of HIV disease in adults in Africa. In Kenya, $11.3 \%$ of blood cultures of 1220 patients with febrile episodes were positive for NTS [34]. In the developing world, HIV infection and AIDS are important risk factors for non-typhoidal salmonellosis and bacteraemia. Salmonella infection is generally acquired from animals or animal products including meat, poultry, milk and eggs. In a study conducted on 201 blood and 48 stool samples from previously diagnosed HIV-1 positive patients attending the out-patient department of the University Teaching Hospital, Lagos four Salmonella typhimurium and two Salmonella enteritidis were recovered from 201 blood samples while there were three Salmonella typhimurium $(6.2 \%)$ and two Shigella flexneri (4.1\%) grew in the 48 stool samples. In their study they observed that, apparent low carriage was attributed to antiretroviral prophylaxix of test groups. It could also be deduced that the media used could also be responsible in that pre- enrichment step in and use of selective isolations technique could affect the yield of Salmonella in blood [35].

Salmonella and Campylobacter are excreted with faeces of the infected hosts and are acquired by ingestion of contaminated foodstuff or direct contact with infected and shedding animals, such as cattle. Thus, HIV infected people must follow several simple rules to reduce the risk of contracting infection. They should avoid eating raw food, which can be contaminated. They should eat meat, poultry, seafood or eggs only after proper cooking. In order to prevent faecal-oral spread directly from animals, HIV-infected people in contact with animals should wash their hands after animal contact and not eat or drink during activities that involve animal contact. Those with extensive exposure to animals, such as farmers, veterinarians and butchers, should wear gloves when exposed to mucous membranes, secretions or tissue of animal.

\subsection{Toxoplasmosis}

Toxoplasmosis is one of the most common zoonoses worldwide. Toxoplasma gondii is a protozoan parasite that infects most species of warm blooded animals, including humans, and can cause the disease toxoplasmosis. The only known definitive hosts for Toxoplasma gondii are members of family Felidae (domestic cats and their relatives). Unsporulated oocysts are shed in the cat's feces which are usually only shed for 1-2 weeks. Oocysts take 1-5 days to sporulate in the environment and become infective. Intermediate hosts in nature (including birds and rodents) become infected after ingesting soil, water or plant material contaminated with oocysts. Oocysts transform into tachyzoites shortly after ingestion. Which become localized in neural and muscle tissue and develop into tissue cyst 
bradyzoites. Cats become infected after consuming intermediate hosts harboring tissue cysts. Cats may also become infected directly by ingestion of sporulated oocysts. Symptoms include cramps abdominal pain, fever, nausea, and vomiting associated with a marked weight loss. Due to immunological deficiency, HIV-infected and AIDS affected patients are at a high risk of contracting cryptosporidiosis. Animals bred for human consumption and wild game may also become infected with tissue cysts after ingestion of sporulated oocysts in the environment [36]. Humans can become infected by eating undercooked meat of animals harboring tissue cysts, consuming food or water contaminated with cat feces or by contaminated environmental samples (such as fecal-contaminated soil or changing the litter box of a pet transplacentally from mother to fetus. Particular risk factors are characterized by immunosuppression and pregnancy. Congenital toxoplasmosis may cause abortion, neonatal death or foetal abnormalities with detrimental consequences for the foetus [37]. It has been observed that the development of encephalitis due to $T$. gondii infection can occur in up to 40 percent of HIV infected patients [38]. These potential routes of infection are important as critical points that could be targeted in strategic plan to try to reduce risks of toxoplasmosis in a susceptible population [39]. A study in Nigeria reported that $29 \%$ of 374 pregnant women in Zaria were seropositive for $\operatorname{Ig} \mathrm{G}$ and $0.8 \%$ to $\operatorname{IgM}$ [40], In their findings, the habit of eating undercooked meat was directly correlated with higher prevalence. In a survey from Maiduguri-North eastern Nigeria, 36.2\% (38 of 105 cats) were seropositive for $T$ gondii [41]. In their study, larger proportions of cats $(56 \%)$ are stray cats in our environment than owned thereby increasing their chances of shedding oocysts in the environment.

The best approach to minimizing the risk of contracting toxoplasmosis in HIV infected patients is by avoiding direct contact with cat faeces, wash hands after handling cats or cat equipment, wear mask and gloves when handling manure or for any soil contact and cook all meat, especially pork.

\subsection{Cryptosporidiosis}

Micro-organisms of the genus Cryptosporidium are considered important zoonotic agents that often induce asymptomatic infections. They represent important pathogens especially in very young or immunocompromised hosts. There are a number of studies on parasites among HIV/AIDS patients in Nigeria, but with varying prevalence rate [42]. Some authors reported a low prevalence of $15.3 \%$ in Benin, Nigeria [43], 28.4\% in Abeokuta, Nigeria [44], while others observed a high prevalence of $79.3 \%$ in Osun state, Nigeria [45]. In 2010 A study of 90 paired blood and single stool specimen in Ilorin, Nigeria, showed that HIV-seropositivity was four times higher for intestinal helminthes such as Strongyloides stercoralis and Giardia lamblia while it was nearly six times higher for coccidian parasites that are AIDS defining such as Cryptoridium spp, Cyclospora and Isospora belli [46]. The most common clinical signs of Cryptosporidium infection are profuse and watery diarrhoea.
In most studies, the occupation, source of water, and lack of access to good toilet facilities of the HIV-infected persons significantly affected the prevalence of intestinal parasitic infections. In order to develop a control strategy to reduce the incidence of infection, the following features of cryptosporidiosis have to be taken into account: Cryptosporidium infections are spread through the ingestion or inhalation of oocysts they are infective when excreted with faeces and are resistant to environmental factors (humidity, temperature).Therefore, minimizing the risks of cryptosporidiosis infections include avoiding direct contact with faeces by maintaining hygiene in food preparation and drinking water sources.

\section{Other Intestinal Parasites}

\subsection{Giardia}

Giardia lamblia is a common aetiological agent of enteric disease throughout the world and it is the most common cause of waterborne outbreaks of diarrhoea in the United States [47] or, more rarely, a cause of food-borne diarrhoea [48, 49]. The most dramatic impact of Giardia lamblia on public health is seen in developing countries, where there is a very high prevalence of infection such as Ethiopia (52.6\%) 41/78 [50] and Brazil 105/265(64\%) by Feitosa et al [51]. Long-term growth retardation of the individual can result from a chronic form of giardiasis [52]. Infection of a host is initiated when the cyst is ingested with contaminated water or, less commonly, food or through direct faecal-oral contact. The cyst is relatively resistant and it is able to survive in a variety of environments [53]. Studies have shown prevalence rates of $4-25 \%$ in dogs [54,55]. Giardia is one of the commonest intestinal pathogens that are diagnosed frequently among HIV-infected subjects, In Nigeria, prevalence varies 13\% [56] and $2 / 360(0.6 \%)$ in Benin city Nigeria [57]. However, the study on assertion that the high prevalence of intestinal parasites could be a factor involved in AIDS progression among African patients has not been fully elucidated in Nigeria

Persons at increased risk of giardiasis include those directly exposed to animals; such as veterinarians, farmers and animal care workers. Other categories at risk include childcare workers, children who attend day care centres, including children in nappies, international travelers and hikers.

\subsection{Microsporidiasis}

Microsporidia are small, sporeforming, obligate intracellular protozoan parasites that are found in the intestine, liver, kidney, cornea, brain, nerves, and muscles of a variety of wild and domesticated animals. More than 100 microsporidial genera and almost 1,000 species have now been identified. Five genera (Enterocytozoon spp., Encephalitozoon spp., Septata spp., Pleistophora sp., and Nosema spp.) and unclassified microsporidia (referred to by the collective term Microsporidium) have been associated with human disease, which appears to manifest primarily in immunocompromised 
persons [58].The environmentally resistant infectious spore is ingested or otherwise contracted with environmental stimulus that activates germination in the spore, releasing the polar tubule. This then multiplies either in contact with the host cytoplasm (as with Encephalitozoon bieneusi) or within a parasitophorous vacuole (in E. interstinalis). They eventually undergo sporogony to further divide and form sporoblasts and release the spores to its surroundings. The spores may then infect other surrounding cells, be transported to new sites within the host, or be excreted in feces or urine to infect other hosts [59].

Microsporidia have not been studied extensively as agents of disease because they are small, stain poorly, evoke little inflammation, and are difficult to diagnose in the absence of electron microscopy [60]. With the advent of HIV and AIDS however, significant numbers of human cases of microsporidiosis have been reported and the zoonotic impact of this infection has recently been demonstrated by isolation of organism in muscle of fish and crustaceans [61]. In AIDS patients the most common microsporidia are Enterocytozoon bieneusi and Encephalitozoon intestinal. The infection is mainly asymptomatic but may induce watery and recurrent diarrhoea, stomach cramps and upset stomach. These symptoms may lead to weight loss and dehydration and can last for weeks and eventual death. In 2005, Microsporidia was first reported in the stool of HIV-infected patients in Nigeria. Faecal samples were taken from 2250 HIV/AIDS Kano and Makurdi in Northern Nigeria, and were investigated for microsporidial infections. In Kano, Enterocytozoon bienuesi was detected in $8(14.17 \%)$ and Encephalitozoon intestinalis in $5(2.60 \%)$ out of 192 HIV/AIDS while from Makurdi showed that Enterocytozoon bienuesi was detected in 13 $(0.65 \%)$ and Encephalitozoon intestinalis in $96(4.78 \%)$ out of 2008 HIV/AIDS patients examined. In their study Microsporidial spores were not found in 1050 HIV-negative patients screened from both areas. Their finding underscores the significance of Microsporidiasis in HIV infection [62]. Survey of Microsporidium in HIV infected individuals Northern Nigeria [63] and in the South West have been reported in Benin [64]. In the same study, serological evaluation showed that $22 / 168(13.10 \%)$ of HIV/AIDS and 2/60 (3.33\%) of HIV-negative patients were seropositive. All the patients with CD4 lymphocytes counts of $<50$ cells $/ \mu 1$ had microsporidia which confirmed the fact that microsporidia is usually observed in patients with low CD4 cells. Possible explanation of fewer patients with low CD4 cells of $<50$ cells $/ \mu 1$ is probably due to the fact that patients in developing countries like Nigeria die from other tropical disease before the CD4 cells drop to the critical level of about 50 cells or less, below which the intestinal microsporidia becomes clinically significant. Most of the HIV/AIDS patients had chronic diarrhoea leading to severe weight loss, this report conforms to earlier findings To reduce the risks of Giradia and microsporidial infection [65], strict rules of thorough hand wash after contact with nappy, animal feaces or litter, after using toilets and washing of vegetables, avoid eating raw fish and drinking of safe water should be adopted. A summary of zoonotic infections associated with HIV in different countries is shown in Table 1

\subsection{Conclusion}

The role of immunothereapy in prevention of zoonotic infection in HIV patient could provide valuable effects. Immunomodulatory antibodies that enhance the immune system to promote the function of immune cells have great promise in preventing and treating opportunistic infections of zoonotic origin in HIV/AIDS patients [67].

While a number of emerging bacterial zoonoses can be transmitted directly or indirectly to immunosuppressed persons, adherence to guidelines for preventive health care, diet, management, and hygiene can greatly reduce the risk of zoonotic transmission.

Veterinarians will continue to play a major role in the diagnosis, treatment, and preventive care of companion animals In addition, they have an important role to play in client and public education, and in functioning as part of a public health team along with other health professionals. Physicians and other health care professionals can benefit from receiving accurate and current information on prevention of zoonotic diseases from members of the veterinary community.

Future population-based studies on immunocompromised patients would greatly help in characterizing their specific risk factors for acquiring zoonotic infections and the evolving epidemiology of food borne diseases must be monitored and understood in order to implement appropriate prevention technologies by the Nigerian government.

Table 1. Zoonotic infections of significance to the HIV-infected individual

\begin{tabular}{|c|c|c|c|c|}
\hline Zoonosis & Sample size & HIV attributed & Country & References \\
\hline Bovine tb & $3,952,000$ & 571,000 & $\begin{array}{l}\text { Southeast } \\
\text { Asia }\end{array}$ & {$[62]$} \\
\hline Bovine $\mathrm{Tb}$ & 86 & $34.9 \%$ & $\begin{array}{l}\text { San Diego } \\
\text { USA }\end{array}$ & {$[62]$} \\
\hline Campylobacter & 160 & $40(70 \%)$ & $\begin{array}{l}\text { Lagos, } \\
\text { Nigeria }\end{array}$ & [63] \\
\hline Salmonella & 495 & $158(31.9 \%)$ & $\begin{array}{l}\text { Malawi, } \\
\text { Africa }\end{array}$ & [64] \\
\hline Toxoplasma & 2525 & $41 \%$ & Nigeria & [65] \\
\hline $\begin{array}{l}\text { Intestinal } \\
\text { Parasites }\end{array}$ & 365 & $105(64 \%)$ & Brazil & [50] \\
\hline $\begin{array}{l}\text { Intestinal } \\
\text { Parasites }\end{array}$ & 137 & $35 \%$ & Pune, India & [66] \\
\hline $\begin{array}{l}\text { Intestinal } \\
\text { Parasites }\end{array}$ & 2000 & $15 \%$ & Nigeria & [56] \\
\hline
\end{tabular}

\section{References}

[1] UNAID "HIV and AIDS estimates". http://www.unaids.org/en/regionscountries/countries/nigeria, 2013

[2] S.F. Altekruse, D.L. Swerdlow. "The changing epidemiology of food borne diseases" American Journal of the Medical Sciences, 311 (1): 23-29, 1996.

[3] S. Grant, C.W. Olsen. "Preventing zoonotic diseases in immunocompromised Persons: The Role of Physicians and Veterinarians" Emerging Infectious Diseases, 5: (1), 1999. 
[4] S.U. Ugbomoiko, L. Ariza, J. Heukelbach. "Parasites of importance for human health in Nigerian dogs: high prevalence and limited knowledge of pet owner" BMC Veterinary Research, 4:49, 2008.

[5] Y.O. Adesiji, A.H. Fagbami. "Epidemiology of Bacterial Zoonosis in Nigeria" Nig. J. Hlth \& Biomed. Sci. 5: 20-25, 2006.

[6] WHO, UNAIDS \& UNICEF. "Towards universal access: scaling up priority HIV/AIDS interventions in the health sector" Federal Ministry of Health Technical Report on the National HIV/Syphilis Sero-prevalence Sentinel Survey Among Pregnant Women Attending Antenatal Clinics in Nigeria. Department of Public Health National AIDS/STI Control Programme; Abuja, Nigeria. 2010.

[7] O. Cosivi, J.M. Grange, C.J. Daborn et al. "Zoonotic tuberculosis due to Mycobacterium bovis in developing countries" Emerg Inf Dis; 4: 59-70, 1998.

[8] C.O. Thoen, J.H. Steele. "Mycobacterium bovis infection in animals and humans" In Steele, J.H., Eds Arnes, IA: Iowa State University Press; 355 pp. 1995.

[9] ANON. "Zoonotic tuberculosis (Mycobacterium bovis): a memorandum from WHO (with participation of FAO)". Bull World Health Organ 72: 851-857, 1994.

[10] W.Y. Ayele, S.D. Neill, J. ZINSSTAG, et al. "Bovine tuberculosis: an old disease but a new threat to Africa" The International Journal of Tuberculosis and Lung Disease 8 (14):924-937, 2004.

[11] A.L. Michel, B. Muller, P.D. Van Helden. "Mycobacterium bovis at the animal-human interface: A problem, or not?" Vet.Microbiol. doi:10.1016/j.vetmic.2009.08.029 2009 (http://www.who.int/zoonoses/Report-Sept06.pdf).

[12] P. Pasquali. "Food Agriculture Organisation-Animal Production and Health. HIV Infections And Zoonoses" Isitituto Superiore di Sanità Rome, Chief, Publishing Management Service, Information Division, FAO;Viale delle Terme di Caracalla, 00100 Rome, Italy. ISBN 92-5-105169-0

[13] WORLD HEALTH ORGANIZATION -WHO. "Global tuberculosis control-surveillance, planning, financing" $W H O$ report. 2008.

[14] A. Ani, S. Okpe, M. Akambi.et al. "Comparison of a DNA based PCR method with conventional methods for the detection of M. tuberculosis in Jos, Nigeria" The Journal of Infection in Developing Countries; 3:470-475 2009.

[15] S.I.B. Cadmus, S. Palmer, M. Okker et al. "Molecular Analysis of Human and Bovine Tubercle Bacilli from a Local Setting in Nigeria” Journal of Clinical Microbiology; 44:29-34, 2006.

[16] S. Ibrahim, C.A. Agada, J.U. Umoh, et al. "Prevalence of bovine tuberculosis in Jigawa State, Northwestern Nigeria" Tropical Animal Health and Production. 42(7):1333-1335, 2010.

[17] S.I.B. Cadmus, M.K. Yakubu, A.A. Magaji, et al. "Mycobacterium bovis, but also M. africanum present in raw milk of pastoral cattle in north-central Nigeria" Trop Anim Health Prod.; DOI 10.1007/s11250-010-9533-2 2010.

[18] D. Ojo, C. Mafiana, A. Adeniran-Sonola "Prevalence of Mycobacterium tuberculosis and human immunodeficiency virus infections in Abeokuta, Ogun State, Nigeria" Nigerian
Journal of Parasitology; 28(1):39-43, 2007.

[19] G. Pennap, J. Giyan, A. Eleboda. "Prevalence of pulmonary tuberculosis (PTB) among people living with HIV/AIDS (PLWHA) in Keffi and its environs" Indian Journal of Microbiology; 49:233-236, 2009.

[20] O.A.T. Alli, D.O. Ogbolu, M.A. Salawu et al. "Molecular Identification And Prevalence Of Mycobacterium Tuberculosis Complex Amongst People Living With HIV In Osun State, Nigeria” Afr J. Clin Exper Microbiol; 11(3)138-145, 2010.

[21] O.A. Jenkins, S.I.B. Cadmus, E.H. Venter et al. "Molecular epidemiology of human and animal tuberculosis in Ibadan, Southwestern Nigeria" Vet Microbiology: doi:10.1016/j.vetmic.2011.02.0372011.

[22] C.A. Glaser, F. J. Angulo, J.A. Rooney. "Animal-Associated Opportunistic Infections among Persons Infected with the Human Immunodeficiency" Virus. Clin Infect Dis. 18:14-24, 1994.

[23] A.O. Coker, R.D. Isokpehi, B.N. Thomas et al. "Zoonotic infections in Nigeria: Overview from a medical perspective" Acta Tropica; 76: 59-63. 2000

[24] R.A. Oberhelman, D.N. Taylor, "Campylobacter infections in developing countries". In I. Nachamkin \& M.J. Blaser, eds. Campylobacter, 2nd edition, pp.139-153. Washington, DC, American Society for Microbiology. 2000.

[25] M.R. Rao, A.B. Naficy, S.J. Savarino et al. "Pathogenicity and convalescent excretion of Campylobacter in rural Egyptian children" American Journal of Epidemiology; 54: 166-173, 2001.

[26] W.A. Ellis, S.D, Neil, JJ O'Brien J.J, HW Ferguson, and J. Hanna, J. "Isolation of Spirillum/Vibrio-like organisms from bovine fetuses," Vet. Records, 100:451-452, 1977

[27] Y.O. Adesiji, A.O. Coker, J.K. Oloke * "Detection of Arcobacters in feces of healthy chickens in Osogbo" Nigeria. Journal of Food Protection, 74(1): 119 - 129, 2011

[28] Y.O. Adesiji YO, J. K. Oloke . "Detection of Arcobacters from faeces of healthy pigs in Osogbo, South Western-Nigeria" Tropical Veterinarian, 27(1): 28 - 35, 2009

[29] O. Vandenberg, A. Dediste, K. Houf, S. Ibekwem , H. Souayah , C. Sammy, N. Douat G. Zissis, J.P. Butzler, and P. Vandamme . Arcobacter Species in Humans" Emerging Infectious Diseases, 2004: 10 10,

[30] H. Kownhar, E.M. Shankar, R. Rajan, A. Vengatesan, U.A Rao . "Prevalence of Campylobacter jejuni and enteric bacterial pathogens among hospitalized HIV infected versus non-HIV infected patients with diarrhoea in southern India". Scand $J$ Infect Dis. 39(10):862-6, 2007

[31] W.C. Levine, J.W. Buehler, N.H. Bean, R.V. Tauxe. "Epidemiology of nontyphoidal Salmonella bacteremia during the human immunodeficiency virus epidemic" J Infect Dis.; 164(1):81-87, 1991.

[32] E.L. Hohmann. "Nontyphoidal salmonellosis" Clinical Infectious Diseases; 32: 263-269, 2001.

[33] CENTER FOR DISEASE CONTROL-CDC. "Common source outbreak of Giardiasis - New Mexico" Morbility and Mortality (Weekly Report Weekly Report. 38(23):405-407, 1989. 
[34] S. Kariuki, C. Gilks, J. Corkill. "Multi-drug resistant non-typhoid Salmonella in Kenya" J Antimicrob Chemother; 38: 425-34, 1996.

[35] A. Adeleye, S. Smith, S. Akanmu et al. "Chromosomally mediated antibiotic resistance in non-typhoidal Salmonellae isolated from HIV patients in Lagos" West Indian med. 57 no.5, 2008.

[36] D.T. John, W. A. Petri. "Markell and Voge's Medical Parasitology" 9th ed. St. Louis: Elsevier Inc. 2006.

[37] J.S. Remington, G. Desmonts. "Toxoplasmosis" In J.S. Remington \& J.O. Klein, eds. Infectious diseases of the fetus and newborn infant, 3rd Edition, pp. 89-195.Philadelphia, USA, WB Saunders. 1990.

[38] J.G. Montoya, J.S. Remington. "Toxoplasmosis" In G.L. Mandell, J.E. Bennett \& R. Dolin, eds. Principles and practice of infectious diseases. pp. 2858-2888. Philadelphia, USA, Churchill Livingstone. 2000

[39] G. L. Mandell, J. E. Bennett, R. Dolin. "Mandell, Douglas and Bennett's Principles and Practice of Infectious Diseases" 6th ed. Philadelphia: Churchill Livingstone, An Imprint of Elsevier. 2005.

[40] B.S. Ishaku, I. Ajogi, J.U. Umoh et al. "Seroprevalence and Risk Factors for Toxoplasma Gondii Infection among Antenatal Women in Zaria, Nigeria" Research Journal of Medicine and Medical Sciences; 4(2): 483-488, 2009.

[41] J. Kamani, A.U. Mani, H.A. Kumshe et al. "Prevalence of Toxoplasma gondii antibodies in cats in Maiduguri, Northeastern Nigeria" Acta Parasitologica 55(1): 94-95, 2010.

[42] F.A. Akinbo, C.E. Okaka, R.L. Danta "Isosporiasis in HIV/AIDS Patients in Edo State, Nigeria" Malaysian Journal of Medical Science. 16(3): 44, 2009.

[43] F.A. Akinbo, C.E. Okaka, R. Omoregie. "Prevalence of intestinal parasitic infections among HIV patients in Benin City, Nigeria".Libyan J Med; 5: 5506, 2010.

[44] M. Okodua, O.A. Adeyeba, Y.M. Talfeng et al. "Age and sex distribution of intestinal parasitic infections among HIV infected subjects in Abeokuta, Nigeria" Online J Health Allied Sci.; 4: 3-5, 2003.

[45] Y.O. Adesiji, R. Lawal, S.S. Taiwo et al. "Cryptosporidiosis in HIV infected patients with diarrhea in Osun State, Southwestern Nigeria" Eur J Gen Med. 4: 119-22, 2007.

[46] S.K. Babatunde, A.K. Salami, J.P. Fabiyi et al. "Prevalence of intestinal parasitic infestation in HIV seropositive and seronegative patients in Ilorin, Nigeria" Ann Afr Med. 9:123-8, 2010 .

[47] R.S. Barwick, D.A. Levy, G.F. Braun et al. "Surveillance for water-borne disease outbreak - United States 1997-1998" Morbility and Mortality (Weekly Report), 49 (SS-4): 1-36. 2000.

[48] E.D. Mintz, M. Hudson-Wragg, P. Mshar et al. "Foodborne giardiasis in a corporate office setting. Journal of Infectious Diseases; 67: 250-253, 1993.

[49] G. Halemariam, A. Kasu, G. Abebe et al. "Intestinal Parasitic infection in HIV/AIDs and HIV Seronegative individual in a teaching hospital in Ethiopia" Jpn J infect Ds. 57:41-43, 2004.

[50] G. Feitosa, A.C. Bandeira, D.P. Sampaio et al. "High prevalence of Giardiasis and Strongyloidiasis among HIV-infected patients in Bahia, Brazil” Braz J Infect Dis 5 :6, 2001.

[51] D. Fraser, N. Bilenko, R.J. Deckelbaum et al. "Giardia lamblia carriage in Israeli Bedouin infants: risk factors and consequences" Clinical Infectious Diseases; 30: 419-424, 2000 .

[52] R.D. Adam, "Biology of Giardia lamblia" Clinical and Microbiology Reviews; 14:447-75, 2001.

[53] N.E. Hahn, C.A. Glaser, D.W. Hird et al. "Prevalence of Giardia in the faeces of pups" Journal of the American Veterinary Medical Association; 192: 1428-1429, 1988.

[54] T.J. Sykes, M.T. Fox. "Patterns of infection with Giardia in dogs in London" Transactions of the Royal Society of Tropical Medicine and Hygiene, 83: 239-240. 1989.

[55] A.S. Saidu, M.D. Bunza, A.U. Abubakar, et al. "A survey of opportunistic infections in HIV seropositive patients attending major hospitals of kebbi state, Nigeria" Bayero journal of pure and applied sciences. 2(1): 70 - 74, 2010.

[56] F.O. Akinbo, C.E. Okaka, R. Richard. "Prevalence of intestinal parasitic infections among HIV patients in Benin City, Nigeria" Libyan J Med, 5: 5506, 2010.

[57] R. Weber, R.T. Bryan, D.A. Schwartz et al. "Human microsporidial infections" Clin Microbiol Rev. 74:426-61, 1994.

[58] J.A. Shadduck "Human Microsporidiosis and Aids" Rev Infect Dis; 11:203-207, 1989.

[59] E.U. Canning. "Microsporidia". In J.P. Kreier, ed. Parasitic protozoa, 2nd Edition, 16: 299-370. San Diego, USA, Academic Press. Center for Disease Control. 1989.

[60] I.C.J. Omalu, A.B. Yako, D.D. Duhlinska et al. "First detection of intestinal microsporidia in Nigeria" Online J Health All Sci.; 3: 4, 2005.

[61] I.C.J. Omalu, D.D. Duhlinska, G.I. Anyanwu et al. "seroprevalence of Microsporidiosis in Immunocompromised Patients in Kano-Nigeria" The Internet Journal of Parasitic Diseases. 8:1, 2007.

[62] D. Park, H. Qin, S. Jain et al. "Tuberculosis due to Mycobacterium bovis in Patients Coinfected with Human Immunodeficiency Virus" Clin Infect Dis. 51 (11): 1343-1346. 2010.

[63] S. Smith, N. Otuonye, E. Omonigbehin, "Prevalence Of Compylobacter Species Amongst HIV/AIDS Patients In Nigeria" Retrovirology, 2(1): 76, 2005.

[64] M.A. Gordon, A.M.K. Kankwatira, G. Mwafulirwa et al. "Invasive Non-typhoid Salmonellae Establish Systemic Intracellular Infection in HIV-Infected Adults: An Emerging Disease Pathogenesis" Clin Infect Dis. 50 (7): 953-962, 2010. O. Falusi, A.L. French, E.C. Seaberg et al. "Prevalence and Predictors of Toxoplasma Seropositivity in Women with and at Risk for Human Immunodeficiency Virus Infection" Clin Infect Dis. 35 (11): 1414-1417, 2002.

[65] S.V. Kulkarni, R. Kairon, S.S. Sane et al. Opportunistic parasitic infections in HIV/AIDS patients presenting with diarrhoea by the level of immunesuppression. Indian $\mathrm{J} \mathrm{Med}$ Res.130 (1): 63-6, 2009.

[66] R. A Weiss, "immunotherapy for HIV Infection" N Engl J Med, 370:379-380, 2014 